Research Article

\title{
Comparison of postoperative analgesic efficacy and safety of parecoxib and ketorolac in patients of inguinal hernia
}

\author{
Ajit M. Zende, Rama R. Bhosale*
}

Department of Pharmacology, R.C.S.M. Government Medical College and C.P.R. Hospital, Kolhapur-416 002, Maharashtra, India

Received: 16 May 2013

Accepted: 8 June 2013

*Correspondence to:

Dr. Rama R. Bhosale,

Email:

bhosale.rama@rediffmail.com

(C) 2013 Zende AM et al. This is an open-access article distributed under the terms of the Creative Commons Attribution License, which permits unrestricted use, distribution, and reproduction in any medium, provided the original work is properly cited.

\begin{abstract}
Background: The present study was conducted to compare postoperative analgesic efficacy and safety profile of intravenous parecoxib with intravenous ketorolac in patients operated for inguinal hernia.

Methods: It was six months, prospective, randomized parallel group, open label study in patients operated for inguinal hernia. Each patient was randomly assigned the analgesic drug treatment and was grouped as control group (ketorolac treated) and study group (parecoxib treated).

Results: The present study has shown that parecoxib has similar analgesic efficacy as that of ketorolac, with parecoxib having significant longer duration of analgesic action. Parecoxib sodium was well tolerated in all patients and most of patients rated parecoxib as well as ketorolac as either good or excellent.

Conclusions: The study demonstrated that parecoxib compares favorably with ketorolac and parecoxib can be recommended as a useful component of postoperative pain control in hernia surgery.
\end{abstract}

Keywords: Ketorolac, Parecoxib, Post-operative pain

\section{INTRODUCTION}

Pain is an unpleasant, subjective feeling registered in the post central gyrus of the cerebral cortex as a response to tissue damage in the organism or functional changes in some part of CNS. Also pain is one of the most common subjective symptoms and the patient's statement is only proof to the doctor that the patient is experiencing pain. ${ }^{1}$ Postoperative pain, which leads to severe patient discomfort, is common problem in anesthesia practice and can be associated with increased respiratory complications and length of the hospital stay. Therefore, anesthetic strategies which reduce the postoperative pain, if used routinely could enhance overall patient cure. ${ }^{2}$ Surprisingly, there is little published data about how much pain to expect after common operations. Management of post-operative pain is complicated and challenging because of large variations in the pain experience and analgesic requirements. ${ }^{3}$ Non-steroidal anti-inflammatory drugs (NSAID) are widely used although clinical response is variable. ${ }^{4}$

NSAIDs inhibit prostaglandin synthesis and exert their anti-inflammatory and analgesic action. ${ }^{5}$ Non-selective NSAIDs like ketorolac inhibits both cyclo-oxygenase (COX)-1 and 2 enzymes. Inhibition of COX-1 is thought to be responsible for damage to gastric mucosa and antiplatelet activity. In contrast, $\mathrm{COX}-2$ is thought to primarily affect generation of prostaglandins involved in inflammation. ${ }^{6}$

Parecoxib sodium is new, highly selective, non-steroidal COX-2 inhibitor. It is a prodrug and produces pharmacologically active selective COX-2 inhibitor valdecoxib on parenteral administration. ${ }^{7}$ Thus the drug that selectivity inhibits COX-2 enzyme should suppress inflammation without causing gastric adverse events and without increasing the risk of bleeding. ${ }^{8}$ 
Hence, in this context it was thought logical to find out the anti-nociceptive efficacy and safety of parecoxib sodium, a selective COX-2 inhibitor, in comparison with ketorolac tromethamine, a non-selective COX inhibitor, as postoperative analgesics. The present study was conducted to compare postoperative analgesic efficacy and safety profile of intravenous parecoxib with intravenous ketorolac in patients operated for inguinal hernia.

\section{METHODS}

The study was conducted in Dr. Lokur Hospital Miraj, a private surgical institute in accordance with the principles of declaration of Helsinki. An informed written and signed consent was obtained from each patient before enrollment in the study.

\section{Design of Study}

It was six months, prospective, randomized, parallel group and open label study in patients operated for inguinal hernia. All the patients operated for inguinal hernia during the period of six month were recruited. Total 69 patients were included in the study. Each patient was randomly assigned the analgesic drug treatment and was grouped as control group (ketorolac treated) and study group (parecoxib treated). Ketorolac group: Patients in this group were administered ketorolac tromethamine $30 \mathrm{mg}$ intravenously as single dose. Out of total number of patients enrolled in study, 32 patients were included in this group. The preparation used was of brand name 'Cadolac 30' manufactured by 'Cadila Pharmaceuticals Pvt. Ltd.' Parecoxib group: Patients in this group were administered parecoxib sodium $40 \mathrm{mg}$ intravenously as single dose. Out of total number of patients, 37 patients were included in this group. The preparation used was of brand name 'Valz' manufactured by 'Torrent Pharmaceuticals Pvt. Ltd.'.

\section{Inclusion Criteria}

All the male patients, operated for inguinal hernia, above 18 years of age who were having a level of pain that measured at least $45 \mathrm{~mm}$ on visual analog scale (VAS) and or categorical pain intensity of moderate to severe type within 6 hours after recovery from anesthesia were selected for the enrollment in the study.

\section{Exclusion Criteria}

Patients operated for hernia other than inguinal hernia were not considered. Patients with previous history of gastro intestinal bleeding, gastric, pyloric or duodenal ulceration were excluded. Patients who had received any analgesic (including neuroleptics) antipsychotics or drugs other than those required for surgery administered within 6 hrs before surgery were excluded. Patients with previous history of hypersensitivity reactions to NSAIDs, COX-2 specific inhibitors, opiates or any analgesic agent were excluded.

\section{Assessment Period}

Each patient of both groups was observed for 24 hours after the administration of respective medication.

\section{Investigations}

Following investigations were carried out for each patient before administration of respective medication and after completion of 24 hours observation period: Hemoglobin gm\%, Total W.B.C. count /cu mm., Differential W.B.C. count as $\%$ of polymorphs, lymphocytes, monocytes and basophils, bleeding time and clotting time, Platelet count / $\mathrm{cu} \mathrm{mm}$, Serum creatinine $\mathrm{mg} \%$, Routine and microscopic urine examination.

\section{Assessment of Efficacy and Safety}

Each patient enrolled in the study was observed for 24 hours after administration of the drug.

\section{Assessment of Pain}

Onset of analgesia: Each patient was observed for $1^{\text {st }}$ one hour by the investigator for onset of analgesia. The patient was asked to indicate the perceptible pain relief (i.e. beginning of the pain relieving effect of drug). The time was noted from administration of study drug to the patient's indication for pain relief in minutes.

Duration of analgesia: This was determined by calculating the time duration between administration of the study drug and reappearance of surface pain. The patient was asked to indicate reappearance of surface pain and the time was noted.

\section{Pain intensity assessment:}

Pain intensity was assessed as score on visual analog scale (VAS) as indicated by patients and as categorical scale.

\section{A) Visual Analog Scale (Vas)}

This was plotted as $10 \mathrm{~cm}$ horizontal line and denoted as severe pain as ' 10 ' $\mathrm{cm}$ and no pain as ' 0 ' $\mathrm{cm}$. Patient was explained about VAS and asked to point out pain intensity according to him at each time interval. This was performed postoperatively before administration of study drug to assess patient's baseline pain intensity. It was also performed at 4, 10, 16 and 24 hours after administration of study drug during the study period. From these measurements, pain intensity difference (PID) was calculated by subtracting pain intensity at each interval from baseline pain intensity.

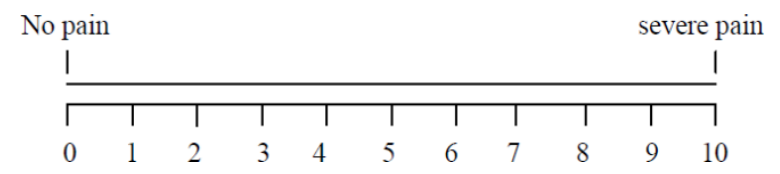




\section{B) Categorical Scale}

According to this pain was categorized as $0-$ No pain, 1 - Mild pain, 2 - Moderate pain and 3 - severe pain. Patient was asked to categorize his pain accordingly at each time interval. It was performed postoperatively before administration of the study drug to categorize patient's baseline pain intensity and to enrol patient with moderate to severe type of pain in the study. It was also performed at 4, 10, 16 and 24 hours intervals after administration of study drug.

\section{C) Pain Relief Scale}

This was plotted as a horizontal line with four divisions, each denoting as 0 - No relief, 1 - Little or some relief, 2 - Good relief, 3 - A lot of relief, 4 - Complete relief. Patient was asked to indicate the pain relief at each time interval i.e. before administration (o hrs) of drug and at 4, 10, 16 and 24 hours. With these measurements mean pain relief scores were determined.

\begin{tabular}{|lllll|} 
No relief & & & complete relief \\
0 & & & & \\
\hline 0 & 1 & 2 & 3 & 4
\end{tabular}

\section{Safety and Tolerability}

It was assessed by measuring the adverse events occurring through out the study and pre and post treatment evaluation of investigations. The adverse events such as nausea, vomiting, dizziness, abdominal pain, headache etc. were assessed for severity and frequency of occurrence by direct observation and indirect questioning. Each patient was assessed for presence of any of events before start of therapy.

\section{Statistical Analysis}

Qualitative type of data was analyzed by applying ' $Z$ ' test for standard error of difference between two proportions and quantitative data was analyzed by using ' $Z$ ' test for standard error of difference between two means. ' $P$ ' value less than 0.05 was taken as significant, that less than 0.001 was taken as highly significant while value $>0.05$ was taken as insignificant.

\section{Patients Global Evaluation}

It was assessed at the end of 24 hours and the patient was asked to rate the study drug received for pain as 1 - Poor, 2 - Fair, 3 - Good, 4 - Excellent.

\section{RESULTS}

Most of patients in both groups were having moderate type $(78 \%)$ and very few $(22 \%)$ were having severe type of pain according to categorical scale. With visual analog scale the mean baseline pain intensity observed for ketorolac group was $6.65 \pm \mathrm{SD}$ and that for parecoxib group was $6.54 \pm \mathrm{SD}$. Both groups are comparable in terms of age, weight and baseline pain characteristics ( $\mathrm{P}$ $>0.05$ ) (Table $1 \& 2$ ).

Table 1: Mean baseline patients characteristics.

\begin{tabular}{|c|c|c|}
\hline & $\begin{array}{l}\text { Ketorolac } \\
\text { Group } \\
\mathbf{n}=\mathbf{3 2}\end{array}$ & $\begin{array}{l}\text { Parecoxib } \\
\text { Group } \\
\mathbf{n}=\mathbf{3 7}\end{array}$ \\
\hline Age (Years) & $42.25 \pm 9.65$ & $42.35 \pm 9.96$ \\
\hline Weight (Kg.) & $59.06 \pm 12.24$ & $63.72 \pm 8.20$ \\
\hline
\end{tabular}

Table 2: Baseline pain characteristics.

\begin{tabular}{|c|c|c|c|}
\hline & & $\begin{array}{l}\text { Ketorolac } \\
\text { Group } \\
\text { n=32 }\end{array}$ & $\begin{array}{l}\text { Parecoxib } \\
\text { Group } \\
\mathbf{n}=\mathbf{3 7}\end{array}$ \\
\hline Categorical & Moderate & $78.12 \%$ & $78.38 \%$ \\
\hline Scale $(\%)$ & Severe & $21.88 \%$ & $21.62 \%$ \\
\hline $\begin{array}{l}\text { V.A.S. } \\
\text { (Mean) }\end{array}$ & & $6.65 \pm 1.04$ & $6.54 \pm 1.26$ \\
\hline
\end{tabular}

The mean value for time for onset of analgesia for ketorolac $(12.43 \pm \mathrm{SD})$ was less than that for parecoxib $(13.29 \pm \mathrm{SD})$ stated that ketorolac had earlier onset of analgesia than parecoxib which was not statistically significant $(P>0.05)$. Also the range of time for onset of analgesia for both groups was same $(9-18 \mathrm{~min})$.

The Mean value of duration of analgesic action for parecoxib $(8.02+\mathrm{SD})$ was greater than that for ketorolac $(7.24+\mathrm{SD})$ and there was statistically significant difference between them stated that parecoxib had longer duration of analgesic action than ketorolac (Table 3).

Table 3: Mean time for onset of analgesia and duration of action.

\begin{tabular}{|lll|l|}
\hline & $\begin{array}{l}\text { Ketorolac } \\
\text { Group } \\
\mathbf{n}=32\end{array}$ & $\begin{array}{l}\text { Parecoxib } \\
\text { Group } \\
\mathbf{n}=37\end{array}$ & P Value \\
\hline $\begin{array}{l}\text { Onset Time } \\
\text { (min) }\end{array}$ & $12.43 \pm 1.83$ & $13.29 \pm 3.13$ & 0.0793 \\
\hline Range & $9-18 \mathrm{~min}$ & $10-18 \mathrm{~min}$ & \\
\hline $\begin{array}{l}\text { Duration } \\
\text { (hrs) }\end{array}$ & $7.24 \pm 1.84$ & $8.02 \pm 1.87$ & $0.0409 *$ \\
\hline
\end{tabular}

* Significant difference between values of two groups $\mathrm{P}$ $<0.05$

Both treatments reduced pain significantly $(\mathrm{p}<0.001)$ at 4, 10, 16, and $24 \mathrm{hrs}$ when compared with baseline pain intensity score. However maximum reduction in pain intensity was observed at 4 and 10 hours for both treatments. When the pain intensities of both groups were compared at designed interval of time, it was observed 
that pain intensity values with parecoxib treatment group at 4 and 10 hours $(0.459 \pm \mathrm{SD}$ and $1.24 \pm \mathrm{SD})$ were significantly lower than that of ketorolac at 4 and 10 hours $(0.218 \pm \mathrm{SD}, 1.156 \pm \mathrm{SD})$. While pain intensity values at 16 and 24 hours intervals of both treatments were not statistically different from each other (Table 4).

Table 4: Mean pain intensity scores.

\begin{tabular}{|lll|l|}
\hline & $\begin{array}{l}\text { Ketorolac } \\
\text { Group } \\
\mathbf{n}=\mathbf{3 2}\end{array}$ & $\begin{array}{l}\text { Parecoxib } \\
\text { Group } \\
\mathbf{n}=37\end{array}$ & P Value \\
\hline O hours & $6.65 \pm 1.04$ & $6.54 \pm 1.26$ & \\
\hline 4 hours & $0.218 \pm 0.41 * *$ & $0.459 \pm 0.68 * *$ & $0.0359 *$ \\
\hline 10 hours & $1.156 \pm 0.66 * *$ & $1.24 \pm 0.85 * *$ & $0.0401 *$ \\
\hline 16 hours & $2.18 \pm 0.58 * *$ & $2.32 \pm 0.77 * *$ & 0.1977 \\
\hline 24 hours & $2.53 \pm 0.70 * *$ & $2.56 \pm 0.67 * *$ & 0.4286 \\
\hline
\end{tabular}

*Significant $\mathrm{P}<0.05$ - States significant difference between values when two groups are compared with each other

** Highly Significant $\mathrm{P}<0.001$ - states high significant difference between values when compared with baseline value for each group.

Greater mean pain intensity difference values were observed at 4 and 10 hours assessment for ketorolac $(6.12$

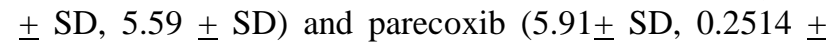
SD) than that at 16 and 24 hours. Statistical comparison of pain intensity difference values at 16 hours interval for ketorolac and parecoxib showed significant difference $(\mathrm{P}$ $<0.05)$ and that at intervals, 4, 10 and 24 hours showed no significant difference for both groups $(\mathrm{P}>0.05)$. This showed that ketorolac significantly lowered pain at 16 hours than parecoxib (Table 5).

Table 5: Mean pain intensity difference scores. (PID scores).

\begin{tabular}{|llll|}
\hline & $\begin{array}{l}\text { Ketorolac } \\
\text { Group } \\
\mathbf{n = 3 2}\end{array}$ & $\begin{array}{l}\text { Parecoxib } \\
\text { Group } \\
\mathbf{n = 3 7}\end{array}$ & P Value \\
\hline 4 hours & $6.12 \pm 1.26$ & $5.91 \pm 0.99$ & 0.3557 \\
\hline 10 hours & $5.59 \pm 0.74$ & $5.29 \pm 0.95$ & 0.2514 \\
\hline 16 hours & $4.65 \pm 0.88$ & $4.21 \pm 0.80$ & $0.0154^{*}$ \\
\hline 24 hours & $4.18 \pm 0.88$ & $4.00 \pm 0.88$ & 0.1949 \\
\hline
\end{tabular}

* Significant difference $\mathrm{P}<0.05$

Both treatment groups showed greater pain relief at 4 hours $(3.81 \pm$ SD, $3.64 \pm S D)$ and at 10 hours $(3.15 \pm$ SD, $3.16 \pm$ SD) than 16 hours $(2.17 \pm$ SD, $2.54 \pm$ SD) and 24 hours $(2.43 \pm \mathrm{SD}, 2.37 \pm \mathrm{SD})$. The values at 4 and 10 hours for both treatments are suggestive of 'a lot of pain relief' while that at 16 and 24 hours are suggestive of 'good' pain relief. There was no significant difference between score values at each interval for both groups $(\mathrm{P}>$ 0.05) (Table 6).

Table 6: Mean pain relief scores (PR Scores).

\begin{tabular}{|llll|}
\hline & $\begin{array}{l}\text { Ketorolac } \\
\text { Group } \\
\mathbf{n = 3 2}\end{array}$ & $\begin{array}{l}\text { Parecoxib } \\
\text { Group } \\
\mathbf{n = 3 7}\end{array}$ & P Value \\
\hline 4 hours & $3.81 \pm 0.39$ & $3.64 \pm 0.47$ & 0.0505 \\
\hline 10 hours & $3.15 \pm 0.36$ & $3.16 \pm 0.49$ & 0.4641 \\
\hline 16 hours & $2.71 \pm 0.44$ & $2.54 \pm 0.59$ & 0.0869 \\
\hline 24 hours & $2.43 \pm 0.70$ & $2.37 \pm 0.63$ & 0.3821 \\
\hline
\end{tabular}

P > $0.05-$ Not Significant.

There is no statistically significant difference for bleeding time and clotting time values between two groups $(\mathrm{P}>$ $0.05)$. All the values, before and after active treatments, were within normal limits ( 2 to $7 \mathrm{~min}$ for bleeding time and 4 to $10 \mathrm{~min}$ for clotting time) (Table 7).

Table 7: Bleeding time and clotting time.

\begin{tabular}{|lllll|}
\hline & \multicolumn{1}{c}{$\begin{array}{l}\text { Before } \\
\text { Treatment }\end{array}$} & $\begin{array}{l}\text { After } \\
\text { Treatment }\end{array}$ & P Value \\
\hline $\begin{array}{l}\text { Bleeding } \\
\text { Time } \\
(\text { min) }\end{array}$ & $\begin{array}{l}\text { Ketorolac } \\
\text { Group }\end{array}$ & $2.77 \pm 0.59$ & $2.89 \pm 0.55$ & 0.2005 \\
\cline { 2 - 5 } & $\begin{array}{l}\text { Parecoxib } \\
\text { Group }\end{array}$ & $2.49 \pm 0.60$ & $2.50 \pm 60$ & 0.4721 \\
\hline $\begin{array}{l}\text { Clotting } \\
\text { Time } \\
(\text { min) }\end{array}$ & $\begin{array}{l}\text { Ketorolac } \\
\text { Group }\end{array}$ & $5.38 \pm 1.15$ & $5.57 \pm 1.12$ & 0.1660 \\
\hline $\begin{array}{l}\text { Parecoxib } \\
\text { Group }\end{array}$ & $5.50 \pm 0.98$ & $5.53 \pm 0.99$ & 0.4483 \\
\hline
\end{tabular}

$\mathrm{P}>0.05-$ not significant

Table 8 shows adverse drug events that were commonly observed after both drug treatments within 24 hours of study period. Out of total, 12 patients in ketorolac group were having nausea $(37.5 \%)$ and same event was observed in 10 patients in parecoxib group (27.02\%). But there was no statistical significance between two values. 9 patients $(28.12 \%)$ in ketorolac group were having vomiting while in parecoxib group the number was 8 $(21.62 \%)$ with no statistically significant difference in two values. Pain in abdomen was seen in $6(18.75 \%)$ patients in ketorolac group and $6(16.21 \%)$ patients in parecoxib group. Though these few events were observed frequently they were of mild to moderate severity and no other serious adverse event was observed in both groups. Rest all other events were observed in very few patients. Statistical comparison of each event in both treatment groups gave no significant difference in values $(\mathrm{P}>$ $0.05)$.

Table 9 shows percent values of ratings given by patients in both treatments groups regarding how they felt given therapy. Majority of patients [ketorolac group (34.37\%, 
$40.62 \%)$ and in parecoxib group $(29.37 \%, 40.54 \%)]$ rated the therapy as 'Good' and 'Excellent' while very few [ketorolac $(9.37 \%, 15.62 \%)$ and in parecoxib $(13.51 \%$, $16.21 \%)$ ] rated the treatments as 'Poor' and 'Fair'. But there was no statistically significant difference between all the ratings for both treatments $(\mathrm{P}>0.05)$.

Table 8: Adverse drug events.

\begin{tabular}{|lll|l|}
\hline & $\begin{array}{l}\text { Ketorolac } \\
\text { Group } \\
\mathbf{n}=32\end{array}$ & $\begin{array}{l}\text { Parecoxib } \\
\text { Group } \\
\mathbf{n}=37\end{array}$ & P Value \\
\hline Back pain & $1(3.12 \%)$ & $1(2.70 \%)$ & 0.4602 \\
\hline Fever & $2(6.25 \%)$ & $1(2.70 \%)$ & 0.4602 \\
\hline Nausea & $12(37.5 \%)$ & $10(27.02 \%)$ & 0.3300 \\
\hline Vomiting & $9(28.12 \%)$ & $8(21.62 \%)$ & 0.2676 \\
\hline $\begin{array}{l}\text { Abdominal } \\
\text { pain }\end{array}$ & $6(18.75 \%)$ & $6(16.21 \%)$ & 0.3936 \\
\hline Dizziness & $4(12.5 \%)$ & $3(8.10 \%)$ & 0.2776 \\
\hline Headache & $6(18.75 \%)$ & $4(10.81 \%)$ & 0.1788 \\
\hline Somnolence & $1(3.12 \%)$ & 0 & 0.3745 \\
\hline $\begin{array}{l}\text { Abnormal } \\
\text { Breath } \\
\text { Sounds }\end{array}$ & $3(9.37 \%)$ & $3(8.10 \%)$ & 0.4286 \\
\hline Pruritus & $2(6.25 \%)$ & $1(2.70 \%)$ & 0.2420 \\
\hline
\end{tabular}

P> 0.05 Not Significant

Table 9: Patients Global Evaluation.

\begin{tabular}{|lll|l|}
\hline & $\begin{array}{l}\text { Ketorolac } \\
\text { Group } \\
\text { n=32 }\end{array}$ & $\begin{array}{l}\text { Parecoxib } \\
\text { Group } \\
\text { n= 37 }\end{array}$ & P Value \\
\hline Poor & $3(9.37 \%)$ & $5(13.51 \%)$ & 0.2946 \\
\hline Fair & $5(15.62 \%)$ & $6(16.21 \%)$ & 0.4761 \\
\hline Good & $11(34.37 \%)$ & $11(29.37 \%)$ & 0.3300 \\
\hline Excellent & $13(40.62 \%)$ & $15(40.54 \%)$ & 0.500 \\
\hline
\end{tabular}

P> 0.05 Not Significant

\section{DISCUSSION}

Predicting which patient will experience severe postoperative pain remains difficult despite the increased knowledge in physiology, pharmacology and anaesthesiology, regarding the pain mechanisms. The percentage of patients unsatisfied by postoperative analgesia remained constant over the last 20 yrs. at approximately $60 \% .^{9,10}$ It is commonly recognized that postoperative pain is primarily determined by the type and duration of the surgery and by the postoperative pain treatment. ${ }^{9}$ However the patients undergoing the same procedures may require plasma levels of opiates varying more than 5 fold to provide satisfactory analgesia. The exact mechanism of inter individual variability remains unknown 11. Pain is determined not only by the characteristic of the noxious stimulus but also by cognitive and behavioral factors. The later present important inter individual variability due to psychological profiles of previous pain experiences, memory and context of occurrence. ${ }^{12}$

Pain is one of the main post-operative adverse outcomes. Single analgesics, either opioid or NSAIDs are not able to provide effective pain relief without side effects such as nausea, vomiting, sedation or bleeding.

Ketorolac tromethamine, the only available IV nonselective COX inhibitor, is an effective analgesic but is associated with significant incidence of untoward effects, including upper gastro-intestinal, ulceration and bleeding, a decrease in renal function and platelet inhibition. ${ }^{13}$ The European Committee for proprietary medicinal products concluded, "Ketorolac has narrow therapeutic margin". ${ }^{14}$ In contrast, the use of COX-2 specific inhibitors may represent a significant therapeutic advance in management of acute pain. Because these compounds produce very little effect on COX-1 they should have larger therapeutic window. A newly developing highly selective COX-2 inhibitor parecoxib has been found to have analgesic properties similar to those of ketorolac ${ }^{14-16}$ without causing gastric adverse events and without increasing the risk of bleeding. ${ }^{8}$ Hence, in this context, it was thought logical to find out anti-nociceptive efficacy and safety of parecoxib sodium - a selective COX-2 inhibitor in comparison with ketorolac tromethamine - a non-selective COX inhibitor as postoperative analgesics in patients operated for inguinal hernia. Though surgical repair techniques of inguinal hernia are considered as minor surgeries carried out under spinal local anesthesia, some patients do have moderate to severe type of postoperative pain and need postoperative analgesic therapy. In present study, majority of patients were having moderate type and very few patients were having severe type of pain. Here we have assessed the efficacy and safety of drugs postoperatively only for 24 hours and within that period no patient needed any additional dose of either of analgesic drugs.

The present study was designed to compare postoperative analgesic efficacy and safety of intravenous parecoxib versus intravenous ketorolac in patients of inguinal hernia. In this study, both ketorolac and parecoxib were found to reduce postoperative pain effectively as assessed by visual analog scale, pain intensity scores and pain intensity difference scores. When pain intensity difference scores of both treatments were compared with each other at designed interval of time, there was no statistically significant difference in values at 16 to 24 hours assessments $(\mathrm{P}>0.05)$, however the values at 4 hours and at 10 hours showed statistically significant difference, (Table. 5) suggesting that ketorolac has more effectively reduced pain at 4 and 10 hours than parecoxib. 
Also both treatments have reduced moderate type of baseline pain intensity to mild type at 4 and 10 hours though values between them show significant difference.

Further, when pain intensity difference (PID) values of both treatments were compared statistically, it was found that there was no statistically significant difference at 4 , 10 , and 24 hour values $(\mathrm{P}>0.05)$ while the values at 16 hours showed statistically significant difference $(\mathrm{P}<$ 0.05) suggesting that ketorolac causes more significant pain intensity difference than parecoxib (Table 5).

But these observed significant differences in pain intensity values and PID values can be ignored if the results of pain relief scores are taken into consideration (Table 6). By use of pain relief scale in present study, the efficacy of treatments is also assessed by measuring pain relief rather than measuring pain intensity alone.

Comparison of pain intensity scores, PID scores and PR scores at designed intervals of time show no statistically significant difference $(\mathrm{P}>0.05)$ between two treatments. Similar findings were seen with all studies reviewed in article by Susan $\mathrm{m}$ et al. ${ }^{18}$ The overall finding of these studies was that efficacy of parecoxib is comparable to that of ketorolac and is significantly greater than placebo.

Observed mean time for onset of analgesia with parecoxib (13.29 \pm SD) is little more than ketorolac (12.43 \pm SD). But both values when compared statistically there was no significant difference observed $(\mathrm{P}>0.05)$. Also the range of onset time for analgesia for both drugs is score $(9-18 \mathrm{~min})$ (Table -3$)$. This result is similar to that of study by Barton S F, Fred F et al. ${ }^{16}$

Further present study has assessed duration of analgesic effect of both treatments by noting the time of administration of particular drug to time at which there is reappearance of surface pain. The results were similar to result of one earlier study by Danniels SE, Grossman E N et al. ${ }^{17}$ But some other studies have shown that both ketorolac and parecoxib have same duration of analgesic action when used postoperatively in extensive procedures like arthroplasty, hysterectomy. ${ }^{13}$ With all above findings of our study and their comparison with other study findings, one can conclude that analgesic efficacy of parecoxib $40 \mathrm{mg}$ is similar to that of ketorolac $30 \mathrm{mg}$ with parecoxib having significant longer duration of analgesic action.

As ketorolac is non-selective COX inhibitor, it is likely to affect the platelet function and consequently the bleeding time. But in the present study, it is observed that there is no significant rise in bleeding time after treatment with ketorolac and parecoxib as compared with bleeding time values observed before treatment with drugs.

Parecoxib sodium was well tolerated in the present study. Adverse events were consistent with common occurrence of symptoms during immediate postoperative period. ${ }^{16}$

Also the present study has assessed overall efficacy of both treatments in terms of patient's global evaluation in which patient himself has rated the treatments as poor, fair, good or excellent. When values of both treatment groups were compared, statistically no significant difference was observed $(\mathrm{P}>0.05){ }^{16}$

With this, present study concluded that parecoxib can replace ketorolac when required for postoperative analgesia. Similar conclusion was drawn in one review article by Peter Kranke, Asrid M Morin et al. ${ }^{19}$

Present study evaluated analgesic efficacy and safety of single intravenous doses of new, injectable COX-2 specific inhibitor -parecoxib sodium in patients with moderate to severe postoperative pain after hernia surgery. The results of this study confirmed the hypothesis that injectable COX-2 specific inhibitor parecoxib sodium would be as effective and well tolerated as COX nonspecific conventional NSAID, ketorolac. In terms of speed of onset of analgesia and general magnitude of analgesia (degree of pain relief and pain intensity), I.V. parecoxib $40 \mathrm{mg}$ was comparable with I.V. ketorolac $30 \mathrm{mg}$ for managing acute post-hernia surgery pain. The duration of pain relief after single dose therapy with parecoxib sodium was similar. Although based on duration of analgesic activity, parecoxib $40 \mathrm{mg}$ has longer duration of action than ketorolac.

The findings of this study provide data regarding the question of relative analgesic potency of $\mathrm{COX}-2$ specific Vs COX non-selective NSAIDs. The study results support the conclusion that inhibition of $\mathrm{COX}-2$ is responsible for observed therapeutic effect of NSAIDs. The comparability of maximum therapeutic doses of ketorolac $30 \mathrm{mg}$ to parecoxib $40 \mathrm{mg}$ suggests that effects of $\mathrm{COX}_{-1}$ inhibition are not associated with analgesic activity, a conclusion consistent with prevailing hypothesis that $\mathrm{COX}-2$ specific agents can have the same efficacy as COX non-selective NSAIDs without added burden of symptoms and adverse effects resulting from COX-1 inhibition.

\section{CONCLUSION}

The present study has shown that parecoxib has similar analgesic efficacy as that of ketorolac, with parecoxib having significant longer duration of analgesic action. Parecoxib sodium was well tolerated in all patients and most of patients rated parecoxib as well as ketorolac as either good or excellent.

The study demonstrated that parecoxib compares favorably with ketorolac and parecoxib can be recommended as a useful component of postoperative pain control in hernia surgery. 
Funding: None

Conflict of interest: None declared

Ethical approval: This study was approved by Institutional Ethical Committee

\section{REFERENCES}

1. Zvonko Kucer. The objective measurement of the pain in orofacial surgery. Actastomatologica NAISSI;2003:19(41).

2. Rose DK, Cohen MM, Yee DA. Changing practice of pain management. Anesth Analg 1997;84:764-72.

3. Eileen P, Lynch, Marrissa A Lazor, Janice E Gallis, John Orav, Lee Goldmann and Edward R Marcantonia. Patient experience of pain after elective non-cardiac surgery. Anaesthesia analgesia 1997;85:117-23.

4. Judith S Walkar and John J Carmody. Experimental pain in healthy subjects: Gender differences in nociception and in response to ibuprofen. Anaesthesia analgesia 1998;86:1257-62.

5. Kuhel FA, Egan RW. Prostaglandins, arachidonic acid and inflammation. Science 1980;210:978-84.

6. Hawkey CJ. New drug classes COX-2 inhibitors. Lancet 1999;353:307-14.

7. Talley JJ, Bartenshaw SR, Brown DL, et al. parecoxib sodium a potent selective COX-2 inhibitor for parenteral administration. J Med Che 2000;43:1661-3.

8. Ormord D, Willington K, Wagstaff AJ. Valdecoxib. Drugs 2002;62(14):2059-71.

9. Raj P. The problem of postoperative pain: An epidemiologic perspective. In: Ferran FM and Vade Bncouer TR - Eds. Postoperative pain management. New York, Churchill Livingstone; 1993:2-3.

10. Brasseur L, Poisson - Salmon A S, Lory C, Chauvain M, Durieux P. Survey on postoperative pain prevalence and severity in the French largest public hospital group. British Journal of Anaesthesia 1996;76:129.

11. C Mammie, M Bernstein, A Morabia, E Klopfenstein, D Sloutskis and Forster. Are their reliable predictors of postoperative pain. Acta Anaesthesiologica Scandinavica 2004;48:234-42.

12. Mc Grath PA. Psychological effects of pain perception. In C Schechter NL, Berdo CB, Yesterm Eds. Psychological aspect of pain perception, pain in infants, children and adolescents. Baltimore: Williams and wilkins 1993:39-63.

13. J Romsing and S. Moiniche. A Systemic review of COX-2 inhibitors compared with traditional NSAIDs or different COX-2 inhibitors for postoperative pain. Acta Anaesthesiol Scandinavica 2004;48:525-46.

14. Lewis S. Ketorolac in Europe. Lancet 1994;343:784.

15. Essmat M, Hegazy MD, Nagala Abd EL - Hady MD, Mai Wedad, Abdullah MD. Comparative study of postoperative analgesic effects of parecoxib vs ketorolac and placebo in cervical disc surgery. Eng $\mathbf{J}$ Anaesth 2003;19:179-82.

16. Barton SF, Fred F, Michel C, Kuss ME, Diane BS, Shobha S, Richard C: Efficacy and safety of intravenous parecoxib sodium in relieving acute postoperative pain following gynecologic laparotomy surgery. Anaesthesiology 2002;97(2):306-14.

17. Daniels S E, Grossman EN, Kuss ME, et al. A double blind randomized comparison of IM and IV administered parecoxib sodium vs ketorolac and placebo in post-oral surgery pain model. Clinical Ther 2001;23:1-14.

18. Cheer SM, Goa KL. Parecoxib (parecoxib sodium). Drugs 2001;61:1133-41.

19. Kranke P, Morin AM, Roewer N, Eberhart LH. Patients' global evaluation of analgesia and safety of injected parecoxib for postoperative pain: a quantitative systematic review. Anesth Analg 2004;99:797-806.

doi:10.5455/2319-2003.ijbcp20130814

Cite this article as: Zende AM, Bhosale RR.

Comparison of postoperative analgesic efficacy and safety of parecoxib and ketorolac in patients of inguinal hernia. Int J Basic Clin Pharmacol 2013;2:414-20. 